\title{
THE NUMERICAL FEM MODEL OF THE KINEMATICS OF THE VIBRATORY SHOT PEENING PROCESS
}

\author{
Stanisław Bławucki', Kazimierz Zaleski ${ }^{1}$ \\ 1 Lublin University of Technology, Faculty of Mechanical Engineering, Department of Production Engineering. \\ Nadbystrzycka 36, 20-618 Lublin, Poland, e-mail: s.blawucki@pollub.pl,k.zaleski@pollub.pl
}

Received: 2017.10.24

Accepted: 2017.11.01

Published: 2017.12.05

\begin{abstract}
:
The paper presents the results of numerical calculations, with the finite element method in the ABAQUS program environment, of the vibratory shot peening process with loose peening elements. The behaviour of shot peening elements was analysed in the kinematic aspect. The impact of the initial deployment of vibratory shot peening elements on their behaviour during processing was investigated, including the displacement, velocity, acceleration and the number of collisions. The way of determining the effectiveness of the processing with the vibratory shot peening was illustrated.
\end{abstract}

Keywords: vibratory shot peening, FEM, vibratory shot peening kinematics, efficiency of vibratory shot peening

\section{INTRODUCTION}

Shot peening means to exert deformations in the surface layer of the workpiece as a result of intense hitting with the peening elements with some kinetic energy. This treatment leads to the improvement of the selected properties of the surface layer of metal workpieces by cold work, which positively affects the performance characteristics of these items, mainly the fatigue strength and surface roughness $[3,10,11]$. The finishing treatment also affects the energetic properties of the surface layer [12]. The deformation is also accompanied by the continuation of compressive stresses in the surface layer, the value of which depends on the technological parameters of shot peening, such as the size and weight of the peening elements used, the frequency of the reciprocal progressive movement of the machining chamber, the amplitude of chamber vibrations and the time of shot peening of the machined parts $[16,18]$. Studies with the positron annihilation method confirmed that the increase of compressive residual stress is associated with an increase in vacancy clusters, as shown in [19]. The metal bearing beads are used as peening elements in the vibratory treatment, usually with the diameters from 2 to $10 \mathrm{~mm}$. The frequency of the vibratory movements usually is selected from the range of $20 \div 30 \mathrm{~Hz}$ and depends on the structure of the device itself. The kinetic energy of the peening component depends on the amplitude, and thus also the size of prints formed on the surface of the workpiece $[4,18]$.

In numerous scientific papers, attempts of the numerical simulation of the shot peening process were undertaken. Majzoobi et al. [13] in the article conducted a three-dimensional simulation of shot peening with the finite element method (FEM) in the LS-DYNA program using the hemisphere models sequentially hitting the surface of the workpiece. The authors adopted the impact speed from 50 to $100 \mathrm{~m} / \mathrm{s}$ and a varying exposure of the tested areas at 4, 6, 8, 9, 13 and 25 consecutive impacts. The stresses developed in the surface layer of the peened samples were studied. In the scientific work, Ciampini et al. [6] performed a numerical simulation of shot peening of the thinwalled sample used for Almen tests. The authors, using the LS-DYNA program, conducted a simu- 
lation of multiple hits with a single bead with a diameter of $6.305 \mathrm{~mm}$ into a disk of the aluminium alloy AA3003-O with a diameter of $10 \mathrm{~mm}$ and thickness of $0.617 \mathrm{~mm}$. The compressive stresses were studied in the surface layer of the disc after hitting with a bullet at a speed from 0.01 to 0.40 $\mathrm{m} / \mathrm{s}$. In the article, Bagherifard et al. [1] developed a numerical model allowing the prediction of micro structural changes in the surface layer of steel $39 \mathrm{NiCrMo} 3$ due to shot peening. Using the computer program Abaqus/Explicit the influence of shot peening of a cubic sample measuring 3 $\mathrm{mm} \times 3 \mathrm{~mm} \times 1.5 \mathrm{~mm}$ was studied with a single bullet and a stream of bullets with a diameter of $0.6 \mathrm{~mm}$. Compressive stresses were examined in the nodes located under the treated surface of the sample, as well as the resulting plastic deformations in the form of movements of the nodes.

Also other research from recent years $[8,14$, 20], presents the results of the numerical FEM simulations of shot peening, including vibratory shot peening. In these works, the authors have focused primarily on the results obtained after shot peening, such as plastic deformations of workpieces, the theoretical amount of surface roughness after the strike with a strong of beads and residual stresses in the surface layer, without conducting the kinematic and dynamic analysis of the peening elements.

Literature in the field of FEM modelling contains numerous examples of metal elements subjected to the process of strengthening through deformation and cold work $[2,7,15,17]$. These works, among others, studied the stresses in the surface layer and deformations caused by the dynamic deformation of thin-walled structures.

There is a lack of scientific works, which would describe the kinematics of the shot peening process, that is the behaviour of peening elements in the machining area, their mutual interaction and movement of these elements. This publication aims to determine the values of displacement, velocity and acceleration of peening elements in the process of vibratory shot peening with the finite element method using the environment of the computer program Abaqus/Explicit.

\section{THEORETICAL INFORMATION}

Kinematics of the vibratory chamber can be compared to the movement of the piston in the combustion engine (Fig. 1). The displace- ment of any point of the vibratory chamber driven by the drive shaft can be written by the following equation [9]:

$$
x=r \cdot\left(1+\frac{\lambda \cdot \sin ^{2} \alpha}{2}-\cos \alpha\right)
$$

where: $r$-eccentricity,

$\lambda$ - the ratio of eccentricity to the crank length,

$\alpha$ - the angle included between the symmetry axis of the vibration chamber and the temporary location of eccentricity on the periphery of the drive shaft.

The initial speed of peening elements placed at the bottom of the vibratory chamber is equal to the speed of the chamber at the initial moment after start-up, when the machine moves vertically up, to the moment of maximum deflection. The speed is the first derivative of displacement over time, which can be written as [9]:

$$
\begin{aligned}
& v=\frac{d x}{d t}=\frac{d x}{d \alpha} \cdot \frac{d \alpha}{d t}=r . \\
& \cdot\left(\sin \alpha+\frac{\lambda \cdot \sin 2 \alpha}{2}\right) \frac{d \alpha}{d t}
\end{aligned}
$$

The equation of the angular velocity of the shaft driving the vibratory chamber can be expressed as follows:

$$
\omega=2 \cdot \pi \cdot f
$$

where: $f$ - frequency of the eccentric movement on the circle.

The final formula for the speed of the vibratory chamber, also describing the initial velocity of the peening elements when the chamber is moving up can be described as [9]:

$$
v=r \cdot \omega \cdot\left(\sin \alpha+\frac{\lambda \cdot \sin 2 \alpha}{2}\right)
$$

The electric motor, driving the eccentric shaft, provides a constant speed, which allows the calculation of the vibratory chamber acceleration as the first derivative of speed over time [9]:

$$
\begin{aligned}
& a=\frac{d v}{d t}=r \cdot \omega^{2} . \\
& \cdot(\cos \alpha+\lambda \cdot \cos 2 \alpha)
\end{aligned}
$$

The equation expressing the second law of dynamics for the case of linear motion can be 


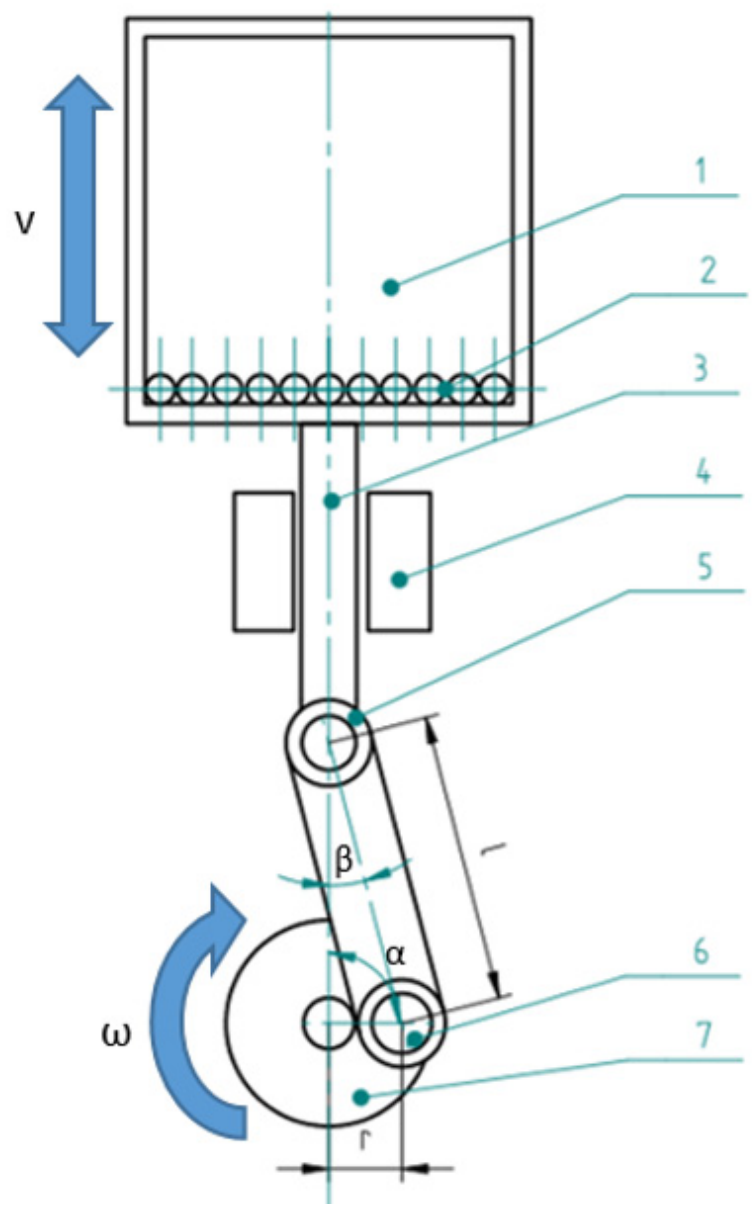

Fig. 1. Diagram of the drive system of the vibratory chamber: 1 - vibratory chamber, 2 - peening elements, 3 - slider, 4 - guide bearing, 5 - crank, 6 - eccentric, 7 - drive shaft

used for calculating the inertia forces of the vibratory chamber with the peening elements:

$$
P_{b}=-m_{w} \cdot a-\sum_{i=1}^{i=n} m_{i} \cdot a
$$

where: $m_{w}-$ vibrator's mass,

$a-$ vibrator's acceleration,

$m_{i}-$ mass of a single peening element.

The equation of the inertia force (6) is only true in the initial stage of the vibratory chamber movement with the peening elements. The entire system can be briefly seen as one concentrated mass moving at a constant speed and a uniform acceleration. With the return movement of the vibratory chamber, the acceleration of the chamber and the acceleration of individual peening elements should be distinguished. Conducting analytical calculations in this field requires specialised knowledge and experience. It is much easier to carry out a kinematic analysis with a finite element method, which allows to obtain a satisfactory accuracy of the calculation results.

\section{DESCRIPTION OF THE RESEARCH}

The numerical calculations were conducted in the Abaqus 6.13 program. A prerequisite to conduct numerical calculations was the definition of material properties of at least one element in the system. It was assumed that the top cover and the bottom of the vibratory chamber are the metal plates with the thickness of $5 \mathrm{~mm}$, which were given the elastic properties. Moreover, it was assumed that the peening elements in the form of spheres and the vibrator's chamber are non-deformable, so they were given the characteristics of rigid bodies. For all elements of the system the hexagonal division grid was used with the finite side length of $0.5 \mathrm{~mm}$ for a bullet, 10 $\mathrm{mm}$ for walls, the bottom and the top plate, with the C3D8R type of elements. At the bottom of the vibratory chamber with working dimensions of the base $50 \times 50 \mathrm{~mm}$ and the height $48 \mathrm{~mm}, 144$ bullets have been uniformly distributed, with the diameter of $4 \mathrm{~mm}$ and the mass of $0.0011 \mathrm{~kg}$ each. 
The reciprocating movement with the frequency of $25 \mathrm{~Hz}$ and the amplitude of $20 \mathrm{~mm}$ was forced on the vibratory chamber. The duration of the simulation was one second with the sampling rate of 2500 measures per second.

Twelve measurement points were selected for the kinematic analysis of the vibratory shot peening process in the form of nodes on the grid of finite elements of the selected beads and one point on the chamber's bottom (Fig. 2a).

Firstly, the displacement was analysed, and then the velocity and acceleration towards the movement of the node placed at the bottom of the vibratory chamber. The data provided a reference point for the results obtained from the beads nodes in the centre of the set $(1,2,3,4)$, in the point most distant from the centre of the set, that is at the corners ( I, II, III, IV) and in the area of the half the width of the panel (A, B, C, D). Visualisations of the initial position of the peening elements and their location in the final time of simulation are shown in figures $2 \mathrm{~b}$ and $2 \mathrm{c}$.

\section{DISCUSSION OF THE RESULTS}

The analysis of the displacement of peening elements and the vibratory chamber was made through the reading of the individual displacements of the nodes of the finite element grid. These nodes were selected for the analysis so as to represent the movement of the given object in the direction related to the movement of the vibratory chamber.

Taking into account the diameter of the bullet and the maximum range of the motion of the bottom plate and the upper vibratory chamber (based on the displacement amplitude) some boundaries were set, within which there was a collision of peening elements with the upper or lower part of the chamber. The width of the range, in which the collision could take place, is $20 \mathrm{~mm}$ both for the lower and the upper compartment (Fig. 3-5). For the lower interval, the minimum level was $-10 \mathrm{~mm}$, and the maximum level was $10 \mathrm{~mm}$. Taking into account the diameter of the bullet and using the appropriate transformations of the output data from the Abaqus program it was found that the minimum value for the upper limit was $34 \mathrm{~mm}$, while the maximum limit was $54 \mathrm{~mm}$. Peaks on the graph, which were within those limits, indicate the occurrence of effective collisions of peening elements with the bottom plate or the plate of the vibratory chamber, for which the workpieces can be mounted. Then the measuring points are outside the aforementioned ranges, it means that the mutual collisions took place between the peening elements during the vibratory chamber movement, which is considered as ineffective collisions during vibratory shot peening.

The effectiveness of treatment with vibratory shot peening can be expressed as a sum of the number of collisions of peening elements with the lower and upper part of the chamber to a total of twice the frequency of the movement of the vibratory chamber:

$$
E=\frac{Z_{e f}}{2 \cdot f_{w}} \times 100 \%
$$

where: $Z_{\text {ef }}$ - the number of effective collisions, which is the sum of the collisions of the peening element with the bottom and top part of the vibratory chamber,

$f_{w}-$ the frequency of the vibratory chamber movement. a)

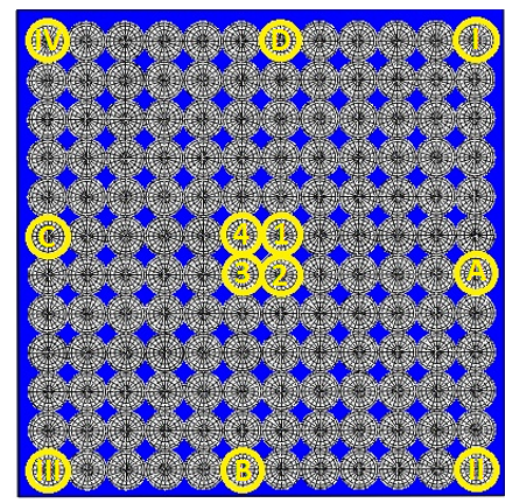

b)
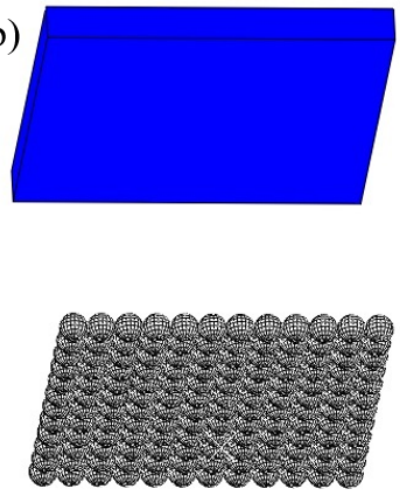

c)

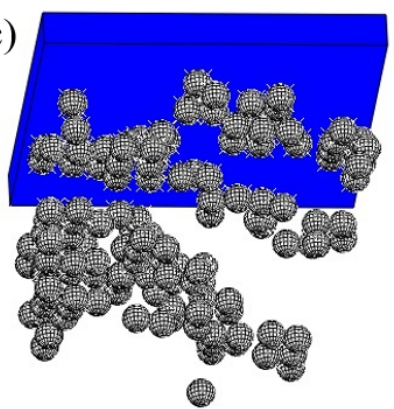

Fig. 2. Machining system - a metal plate and peening beads: a) measurement points, b) a view of peening elements in the initial moment, c) a view of peening elements in the final moment 


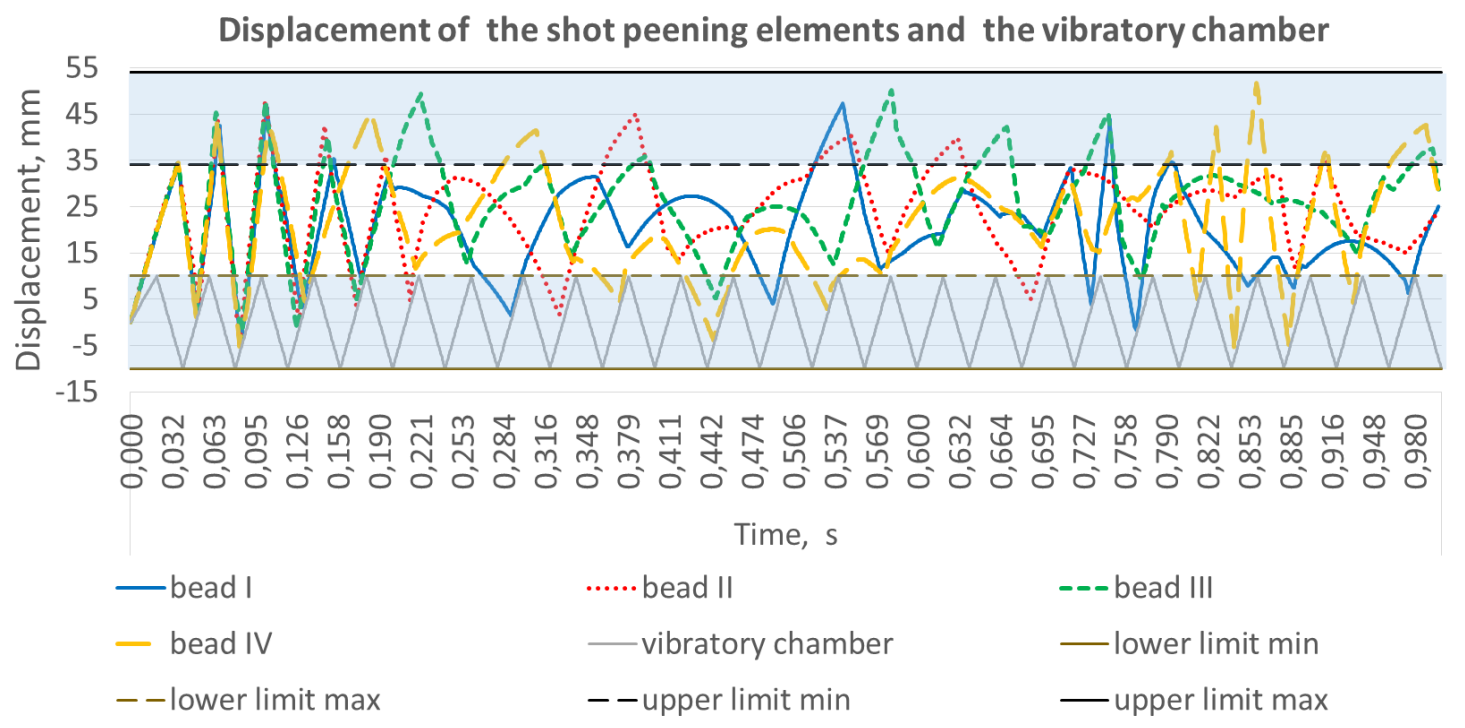

Fig. 3. The displacement of peening elements arranged at the corners at the bottom of the vibratory chamber, as well as the displacement of the vibratory chamber in the time function

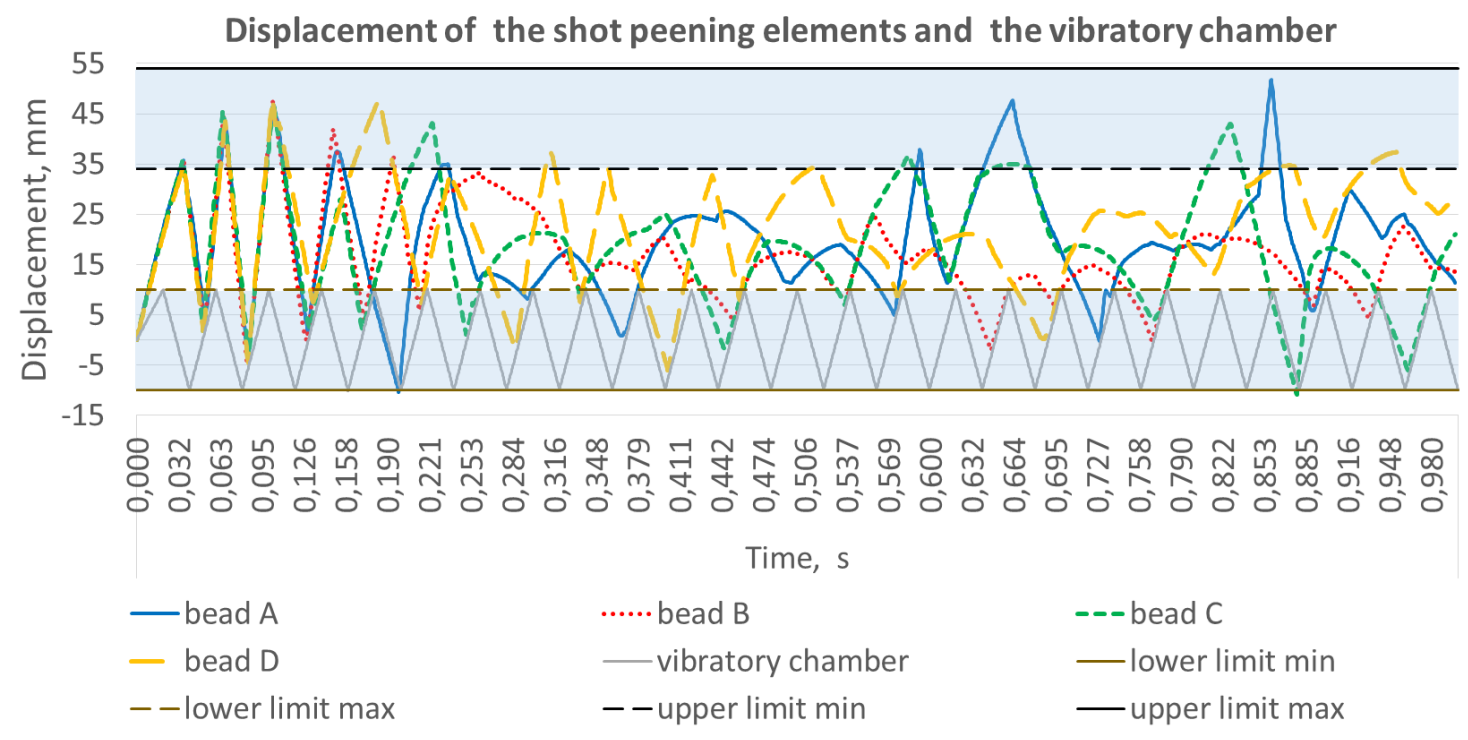

Fig. 4. The displacement of the peening elements distributed on the bottom of the vibratory chamber in the middle of the plate's width, as well as the displacement of the vibratory chamber in the time function

The average number of effective collisions in one second of the FEM simulation was about 18 collisions, which at a frequency of processing amounting to $25 \mathrm{~Hz}$ gives the burnishing efficiency at the level of $36 \%$. The smallest number of effective collisions was noted for the bullets in the middle of the bottom of the vibratory chamber, which can be explained by the formation of a conglomeration of peening elements during processing. The target result is the efficiency of collisions amounting to $100 \%$.

The speed of peening elements was determined similarly to the case of shift analyses. The speed was obtained as a derivative of the road $\Delta \mathrm{x}$ travelled by the peening element in time $\Delta t$. The absolute velocity of the vibratory chamber was $1000 \mathrm{~mm} / \mathrm{s}$. Indications in the form of peaks in figures 6-8 concern the speed obtained by individual peening elements. The maximum absolute speed obtained for the bead was close to 5000 $\mathrm{mm} / \mathrm{s}$. Such an element has enough power to exert elastic-plastic deformations of the surface layer of the workpiece [18].

The periodic increase of peening elements can be observed, and then a period of blanking the speed. The maximum speed, for the absolute value, is formed after the effective collisions of peening elements with the bottom or top part of 


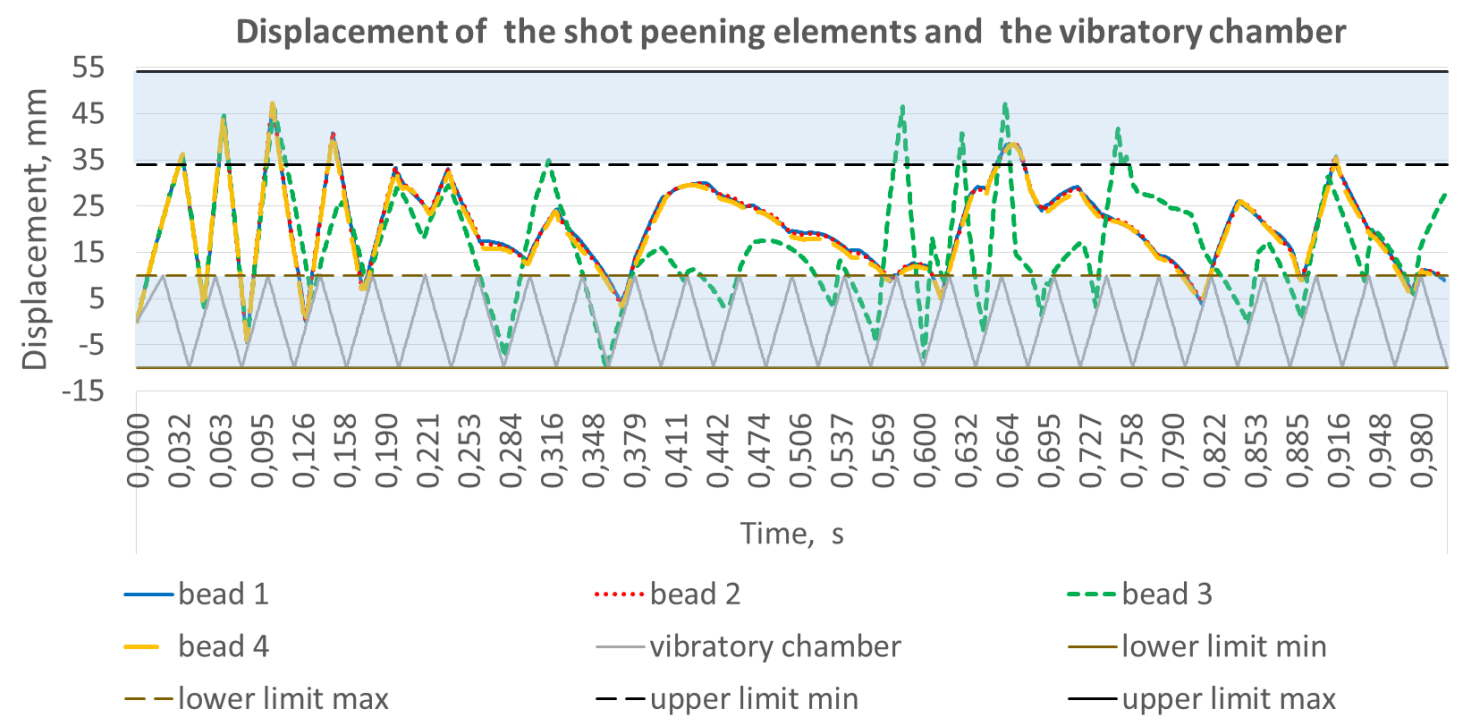

Fig. 5. The displacement of the peening elements distributed in the middle of the bottom of the vibratory chamber, as well as the displacement of the vibratory chamber in the time function

the vibratory chamber, while the minimum speed is strictly related to the collisions of peening elements with each other, when the blanking of their speed occurs. Then, the peening elements fall under gravity to the bottom of the vibratory chamber, which accelerates them to the maximum speed. Then, the entire cycle of vibratory shot peening is repeated.

Acceleration measurements of peening elements were performed as in the case of the movement and speed analysis. Acceleration was obtained as the derivative of $\Delta \mathrm{v}$ speed of the peen- ing elements in time $\Delta \mathrm{t}$. Diagrams of speed and movement are very close to each other in terms of shape and periodicity of the occurrence of certain phenomena of a mechanical nature (Fig. 10 -12).

The maximum acceleration recorded was over $20000000 \mathrm{~mm} / \mathrm{s}^{2}$, which is approximately a value ten times less than the acceleration of a projectile fired from a firearm [5].

At the initial moment of the collision of the selected peening element with the bottom of the vibratory chamber this element is accelerated. Then, the acceleration of the bead changes by

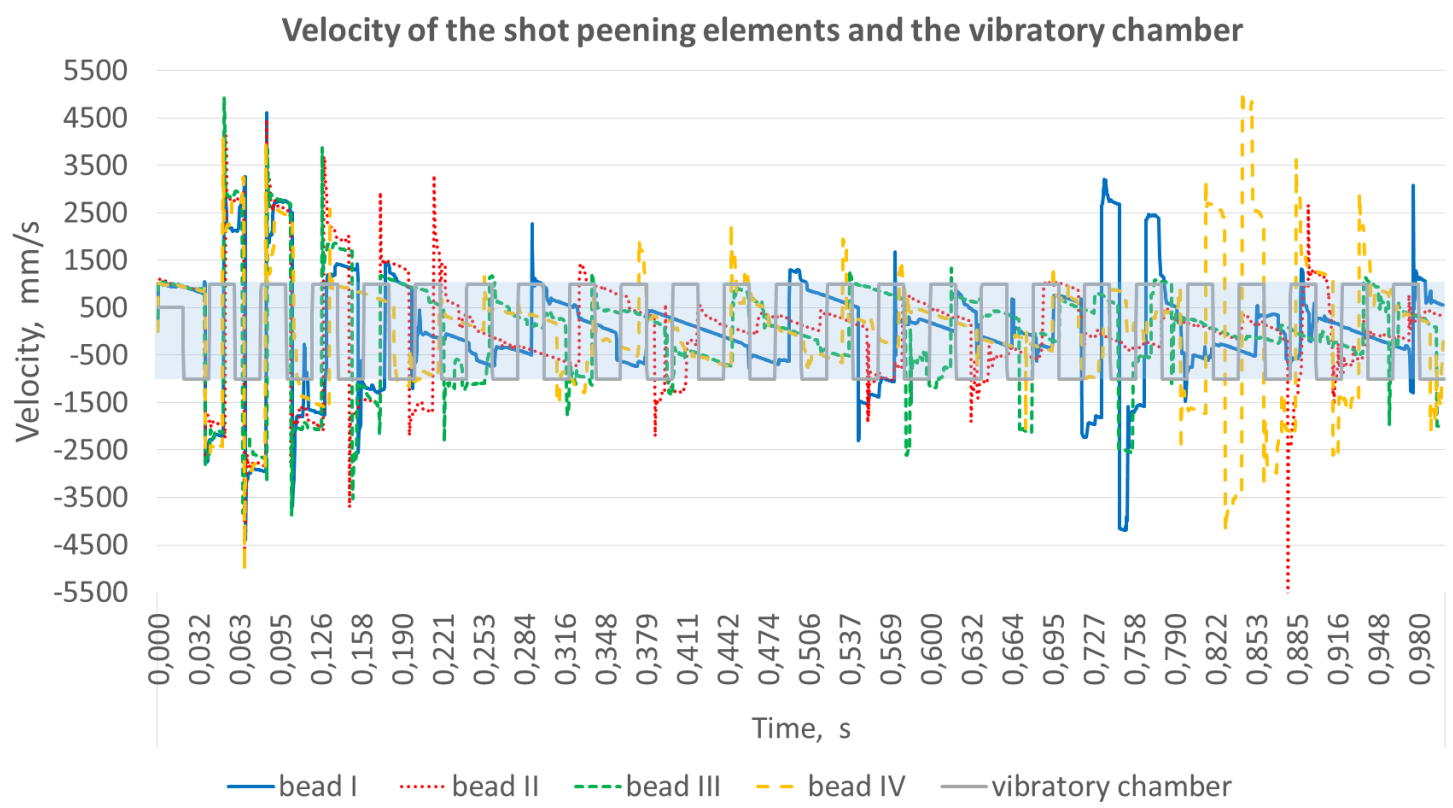

Fig. 6. The speed of peening elements distributed in the corners at the bottom of the vibratory chamber, as well as the speed of the vibratory chamber in the time function 


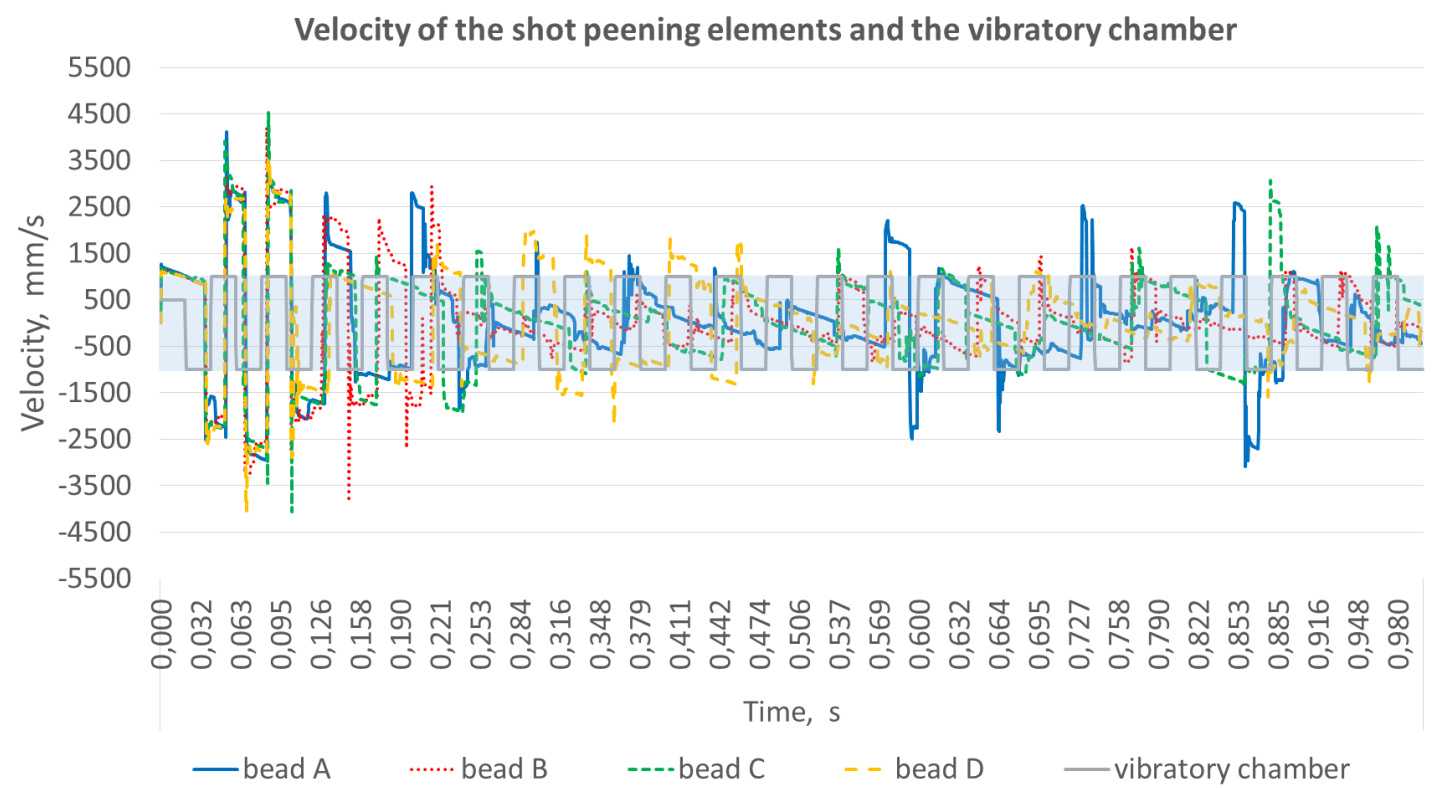

Fig. 7. The speed of peening elements distributed on the bottom of the vibratory chamber in the middle of the plate's width, as well as the speed of the vibratory chamber in the time function

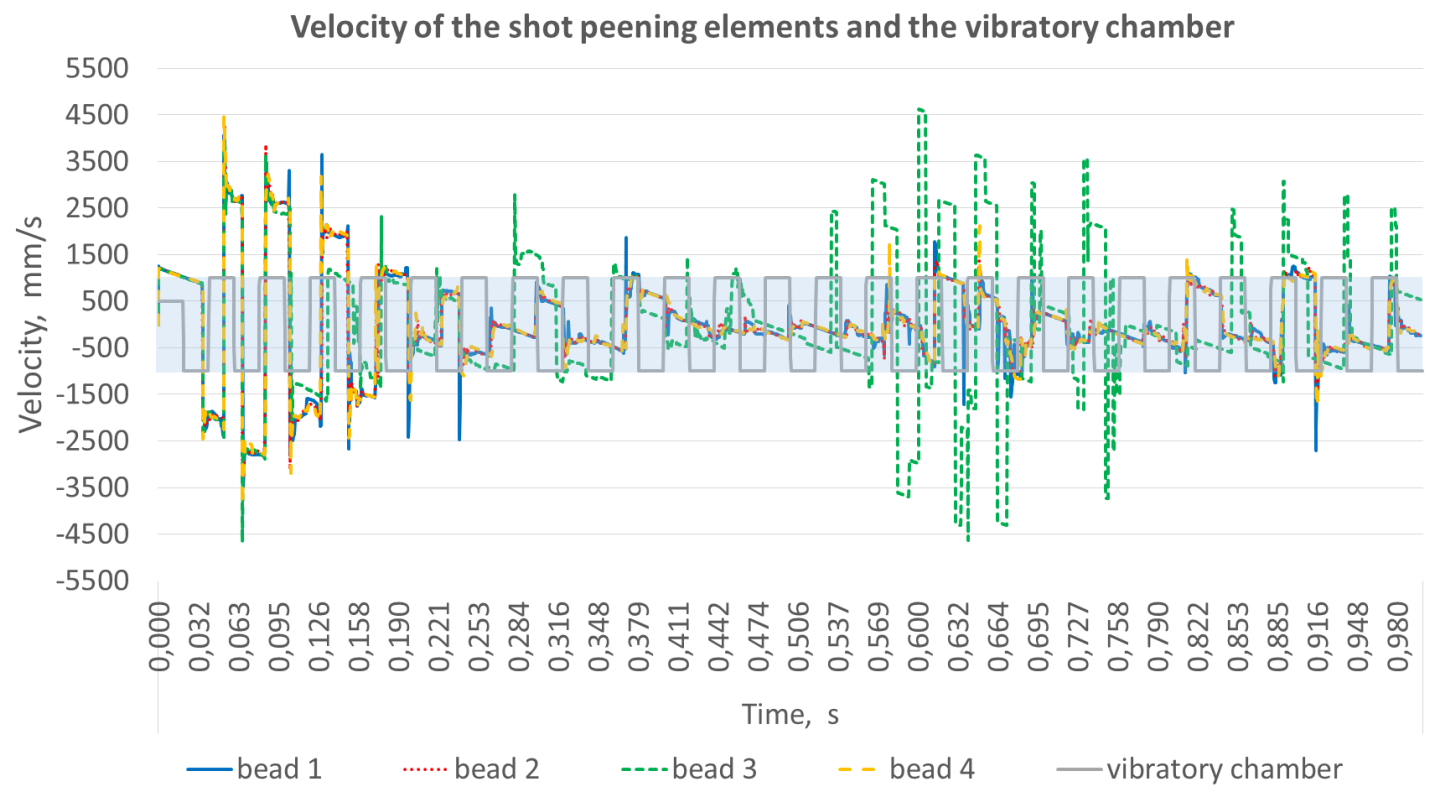

Fig. 8. The speed of peening elements distributed in the middle of the bottom of the vibratory chamber, as well as the speed of the vibratory function in the time function

the delay value due to colliding with other beads taking part in the vibratory shot peening treatment process.

\section{CONCLUSIONS}

The numerical analysis with the finite element method makes it possible to carry out complex research on the kinematics of the shot peening.
The only limitation is the computing power of the workstation, which is necessary to resolve the issue with the required accuracy. Introducing some necessary simplifications and generalizations to the numerical model of shot peening, several conclusions can be made concerning the obtained research results.

On the basis of data from numerical analyses, it has been observed that the effectiveness of shot peening is approximately $40 \%$, assuming that the 


\section{Acceleration of the shot peening elements and the vibratory chamber}

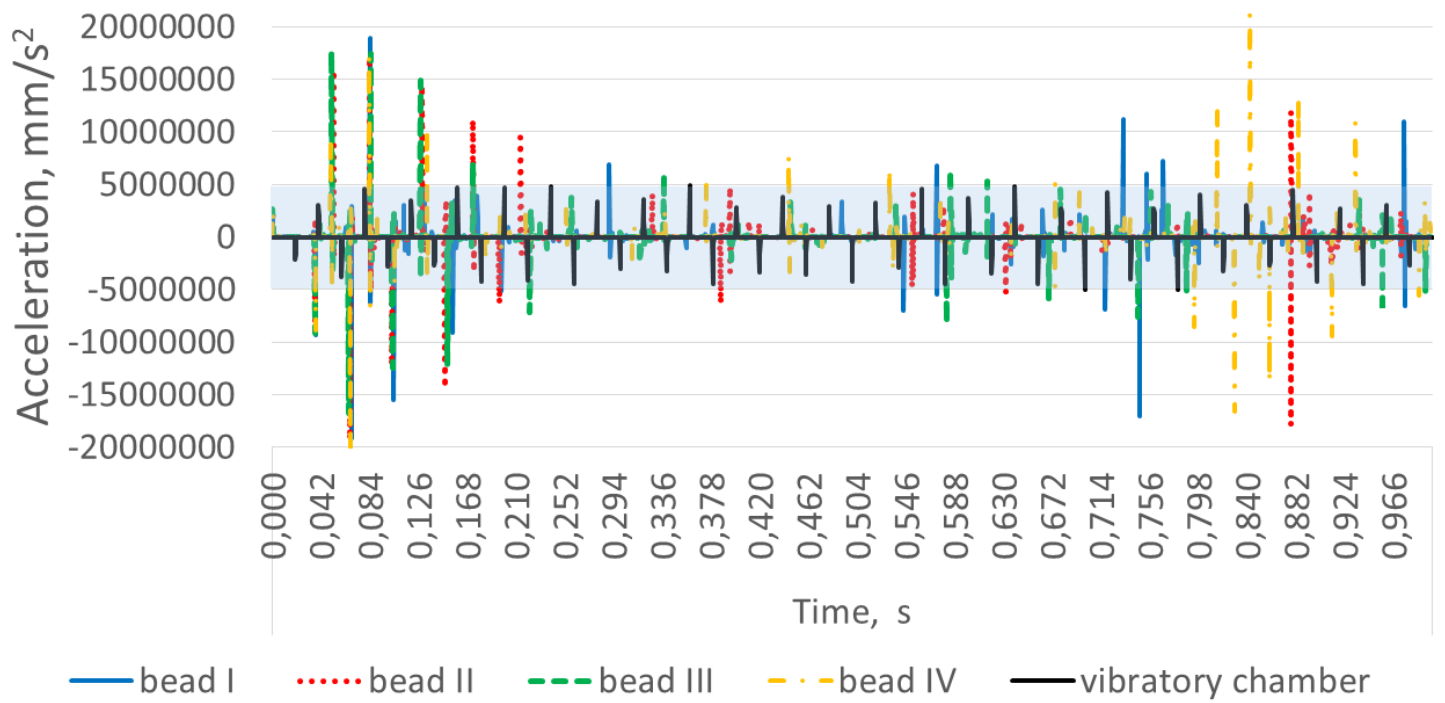

Fig. 9. Acceleration of peening elements distributed in the corners on the bottom of the vibratory chamber, as well as the acceleration of the vibratory chamber in the time function

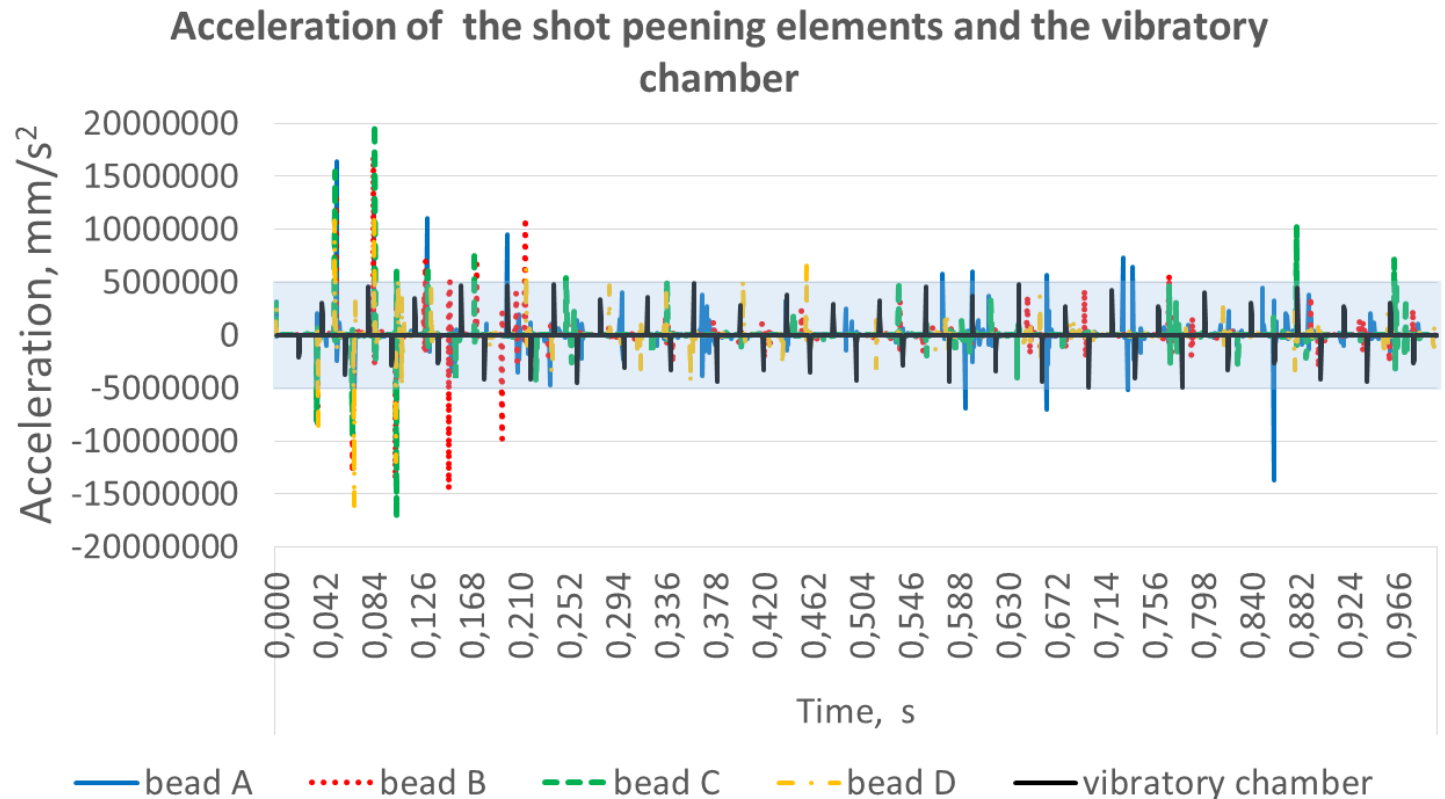

Fig. 10. Acceleration of peening elements distributed on the bottom of the vibratory chamber in the middle of the plate's width, as well as the acceleration of the vibratory chamber in the time function

chamber is filled with one layer of peening elements with a diameter of $4 \mathrm{~mm}$.

The displacement and maximum speed of peening elements are largely dependent on the area in which these elements are located. Due to the observed tendency to the formation of agglomerations of bullets in the central area of the vibratory chamber during processing, a slight- ly lower effectiveness of burnishing has been noted in this area to, for example, areas in the corners of the chamber.

Analysing the spectra of the velocity and acceleration of the peening elements it can be concluded that the vibratory processing with shot penning is periodic in nature, where there are moments of intense interaction of the peen- 


\section{Acceleration of the shot peening elements and the vibratory chamber}

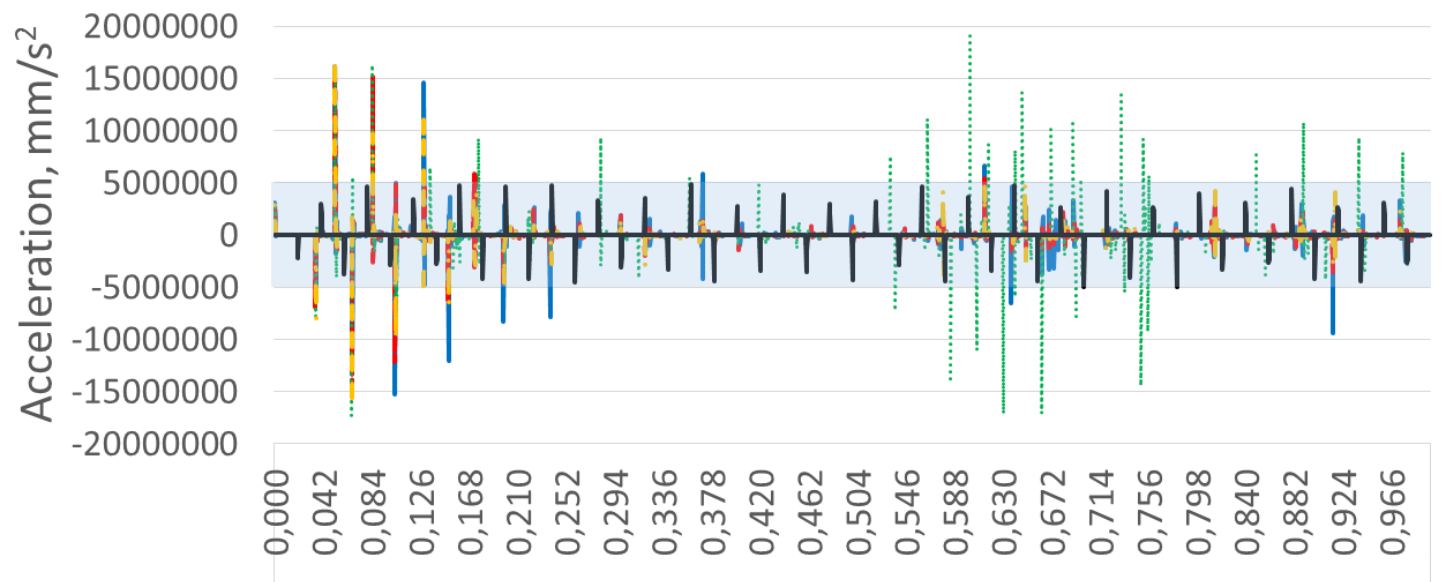

Time, s

-bead $1 \quad$----bead $2 \quad$......... bead $3 \quad-$ - bead $4 \quad$ vibratory chamber

Fig. 11. Acceleration of peening elements distributed in the middle of the bottom of the vibratory chamber, as well as the acceleration of vibratory chamber in the time function

ing elements, and the periods during which the reduction of burnishing efficiency occurs. At the frequency of $25 \mathrm{~Hz}$ of chamber movement per second two periods of increasing the intensity of shot peening were observed.

\section{REFERENCES}

1. Bagherifard S., Ghelichi R., Guagliano M.: A Numerical Model of Severe Shot Peening (SSP) to Predict the Generation of a Nanostructured Surface Layer of Material, Surface \& Coatings Technology, 2010, 24, 204, 4081-4090.

2. Bartnicki J., Pater Z., Gontarz A., Kazanecki J., Samolyk G.: The Research on Rolling-Extrusion Process of Full and Hollowed Parts. Steel Research International, 2008, 364-368.

3. Beer K., Palka K., Surowska B., Walczak M.: A Quality Assessment of Casting Dental Prosthesis Elements. Eksploatacja I Niezawodnosc - Maintenance and Reliability, 2013, 3, 15, 230-236.

4. Blawucki S., Zaleski K.: The Effect of The Aluminium Alloy Surface Roughness on the Restitution Coefficient. Advances In Science And Technology-Research Journal, 2015, 9, 27, 66-71.

5. Bobrowski C.: Fizyka : krótki kurs. Wydawnictwa Naukowo-Techniczne, Polska, Warszawa 2007.

6. Ciampini D., Papini M., Spelt J.K.: Impact Velocity Measurement of Media in a Vibratory Finisher. Journal of Materials Processing Technology, 2007, 183, 347-357.
7. Debski H., Koszalka G., Ferdynus M.: Application of FEM in the Analysis of the Structure of a Trailer Supporting Frame with Variable Operation Parameters, Eksploatacja i Niezawodnosc - Maintenance and Reliability, 2012, 2, 14, 107-113.

8. Klemenz M., Schulze V., Rohr I., Löhe D.: Application of the FEM for the prediction of the surface layer characteristics after shot peening. Journal of Materials Processing Technology, 2009, 209, 4093-4102.

9. Kluczyk M.: An Analysis of the Kinematics and Dynamics of a Shaft-Piston System in a Single Cylinder Four-Stroke Engine ZS. Scientific Journal of Polish Naval Academy 2014, 3, 198, 51-62.

10. Korzynski M.: A Model of Smoothing Slide BallBurnishing and an Analysis of the Parameter Interaction. Journal of Materials Processing Technology, 2009, 1, 209, 625-633.

11. Kulakowska A., Kukielka L.: Numerical Analysis and Experimental Researches of Burnishing Rolling Process with Taking into Account Deviations in the Surface Asperities Outline After Previous Treatment. Steel Research International, 2008, 42-48.

12. Kwiatkowski M. P., Klonica M., Kuczmaszewski J., Satoh S.: Comparative Analysis of Energetic Properties of Ti6Al4V Titanium and EN-AW2017A(PA6) Aluminum Alloy Surface Layers for an Adhesive Bonding Application. Ozone-Science \& Engineering, 2013, 3, 35, 220-228.

13. Majzoobi G. H., Azizi, R., Nia, A. A.: A ThreeDimensional Simulation of Shot Peening Process 
Using Multiple Shot Impacts. Journal of Materials Processing Technology, 2005, 164, 1226-1234.

14. Mylonas G. I., Labeas G.: Numerical Modelling of Shot Peening Process and Corresponding Products: Residual Stress, Surface Roughness and Cold Work Prediction. Surface \& Coatings Technology, 2011, 19, 205, 4480-4494.

15. Pater Z., Bartnicki J., Gontarz A., Weronski W.: Numerical Modeling of Cross - Wedge Rolling of Hollowed Shafts. Materials Processing and Design: Modeling, Simulation and Applications, Pts 1 and 2, 2004, 712, 672-677.

16. Sledz M., Stachowicz F., Zielecki W.: The Effect of Shot Peening on the Fatigue Strength of Steel Sheets. Kovove Materialy - Metallic Materials, 2015, 2, 53, 91-95
17. Teter A.: Static and Dynamic Interactive Buckling of Isotropic Thin-Walled Closed Columns with Variable Thickness. Thin-Walled Structures, 2007, 10-11, 45, 936-940.

18. Zaleski K.: The Effect of Vibratory and Rotational Shot Peening and Wear on Fatigue Life of Steel. Eksploatacja I Niezawodnosc - Maintenance and Reliability, 2017, 1, 19, 102-107

19. Zaleski R., Zaleski K.: Positron Annihilation in Steel Burnished by Vibratory Shot Peening. Acta Physica Polonica A, 2006, 5, 110, 739-746.

20. Zimmermann M., Klemenz M., Schulze V., Lohe D.: Numerical Studies on the Influence of Thickness on the Residual Stress Development During Shot Peening. High Performance Computing In Science And Engineering ,08, 2009, 481-492. 